\title{
Nonsteroidal anti-inflammatory drugs (NSAIDs), cyxlooxygenase-2 selective inhibitors (coxibs) and gastrointestinal harm: review of clinical trials and clinical practice
} R Andrew Moore*1,2, Sheena Derry ${ }^{1}$, Ceri J Phillips ${ }^{2}$ and Henry J McQuay ${ }^{1}$

Address: ${ }^{1}$ Pain Research and Nuffield Department of Anaesthetics, University of Oxford, The Churchill, Headington, Oxford, OX3 7LJ, UK and ${ }^{2}$ School of Health Sciences, University of Wales Swansea, Singleton Park, Swansea, SA2 8PP, UK

Email: R Andrew Moore* - andrew.moore@pru.ox.ac.uk; Sheena Derry - sheena.derry@pru.ox.ac.uk; Ceri J Phillips - C.J.Phillips@swansea.ac.uk; Henry J McQuay - henry.mcquay@pru.ox.ac.uk

* Corresponding author

Published: 20 October 2006

BMC Musculoskeletal Disorders 2006, 7:79 doi:10.1 186/147/-2474-7-79

This article is available from: http://www.biomedcentral.com/I47/-2474/7/79

(C) 2006 Moore et al; licensee BioMed Central Ltd.

This is an Open Access article distributed under the terms of the Creative Commons Attribution License (http://creativecommons.org/licenses/by/2.0), which permits unrestricted use, distribution, and reproduction in any medium, provided the original work is properly cited.
Received: 19 July 2006

Accepted: 20 October 2006

\begin{abstract}
Background: Gastrointestinal harm, known to occur with NSAIDs, is thought to be lower with NSAID and gastroprotective agent, and with inhibitors selective to cyclooxygenase-2 (coxibs) at usual plasma concentrations. We examine competing strategies for available evidence of reduced gastrointestinal bleeding in clinical trials and combine this evidence with evidence from clinical practice on whether the strategies work in the real world, whether guidance on appropriate prescribing is followed, and whether patients adhere to the strategies.
\end{abstract}

Methods: We used a series of systematic literature searches to find full publications of relevant studies for evidence about the efficacy of these different gastroprotection strategies in clinical trials, and for evidence that they worked and were adhered to in clinical practice - whether they were effective. We chose to use good quality systematic reviews and meta-analyses when they were available.

Results: Evidence of efficacy of coxibs compared to NSAIDs for upper gastrointestinal bleeding was strong, with consistent reductions in events of about $50 \%$ in large randomised trials (34,460 patients), meta-analyses of randomised trials (52,474 patients), and large observational studies in clinical practice (3,093 bleeding events). Evidence on the efficacy of NSAID plus gastroprotection with acid suppressants (proton pump inhibitors, PPIs, and histamine antagonists, H2As) was based mainly on the surrogate measure of endoscopic ulcers. The limited information on damage to the bowel suggested that NSAID plus PPI was more damaging than coxibs.

Eleven observational studies studied I.6 million patients, of whom 91 I,000 were NSAID users, and showed that $76 \%$ (range $65 \%$ to $90 \%$ ) of patients with at least one gastrointestinal risk factor received no prescription for gastroprotective agent with an NSAID. The exception was a cohort of US veterans with previous gastrointestinal bleeding, where $75 \%$ had gastroprotection with an NSAID. When gastroprotection was prescribed, it was often described as inadequate. A single study suggested that patient adherence to prescribed gastroprotection was low.

Conclusion: Evidence for efficacy of gastroprotection strategies with NSAIDs is limited. In clinical practice few patients who need gastroprotection get it, and those who get it may not take it. For coxibs, gastroprotection is inherent, although probably not complete. 


\section{Background}

Chronic pain affects one adult in five in Europe [1], limits functioning, and is an enormous problem for healthcare. Osteoarthritis, rheumatoid arthritis, and back pain have the largest negative impact on quality of life of any chronic condition (including cancer, chronic respiratory conditions, or heart disease) for people living in the community [2].

NSAIDs are effective analgesic and anti-inflammatory drugs that form the main pharmacological approach to treating various forms of pain, and particularly chronic musculoskeletal pain, but have a number of known adverse effects. NSAIDs (and aspirin) are associated with upper [3] and lower [4-6] gastrointestinal harm, acute renal failure $[7,8]$ and congestive heart failure $[9,10]$. Coxibs are differentiated pharmacologically from traditional NSAIDs by inhibiting only the cyclooxygenase-2 enzyme, and clinically by lower rates of upper and lower gastrointestinal harm. All of these drugs (aspirin, NSAIDs, and coxibs) may also be associated with increased risk of cardiovascular harm, although increased cardiovascular events are not generally seen for coxibs compared with NSAIDs or placebo in studies in patients with arthritis. Meta-analyses of large numbers of patients in trials of individual coxibs [11] and all coxibs [12] found no systematic difference between coxib and NSAID. Meta-analysis of recent observational studies with 3.5 million patients showed that cardiovascular effects of some NSAIDs (particularly diclofenac) were greater than some coxibs [13]. Our views on rare but serious harm can be directed by the amount of information available.

This paper concentrates on differences between NSAIDs and coxibs for causing gastrointestinal harm. Possible strategies for reducing gastrointestinal harm from NSAIDs alone include use of coxib, NSAID plus PPI, NSAID plus H2A, or NSAID plus misoprostol. Since misoprostol is prescribed rarely in the UK [14] and elsewhere because of other gastrointestinal adverse events it causes, the competing strategies for gastroprotection are use of histamine antagonists or proton pump inhibitors with NSAID, or coxib.

The effectiveness of any strategy is the product of efficacy in clinical trials, and the usability of the strategy in clinical practice. For drugs, this means that prescribing of a medicine is appropriate, and that patients prescribed the medicine take it. Medicines not taken cannot be effective.

We examine each competing strategy in terms of available evidence for reduction of gastrointestinal bleeding in clinical studies and combine it with evidence from clinical practice on whether the strategies work in the real world, whether guidance on appropriate prescribing is followed, and whether patients are able or willing to adhere to the strategies over the longer term.

\section{Methods}

We searched for evidence from systematic reviews, randomised trials and observational studies of clinical practice in several areas:

1. Evidence of reduction of upper and lower gastrointestinal bleeding rates with coxibs compared with non-selective NSAIDs; in particular, evidence that results obtained from clinical trials were also seen in clinical practice.

2. Evidence concerning levels of prescribing of gastroprotective strategies with non-selective NSAIDs to patients with one or more risk factors for gastrointestinal bleeding, and whether prescribing was described as appropriate against any prescribing guidance.

3. Evidence concerning adherence to prescribed gastroprotective strategies with non-selective NSAIDs.

A number of different search strategies were used to find full publications of studies relating to these outcomes. These were predominantly free-text searches of PubMed and the Cochrane Library (to December 2005), bibliographies of papers and reviews, and discussions with experts. Where evidence was available, we chose the highest level available, preferably from good quality systematic reviews and meta-analyses. The sensitivity of electronic databases for observational studies is known not to be high $[15,16]$, so reviews and bibliographies were extensively searched for references to studies of prescribing strategies in clinical practice.

Any study that might have contributed was obtained in full and read. For inclusion, the only criterion was that of full publication; abstracts or posters were not accepted. Formal quality scoring of included studies was not considered appropriate because of the likely mix of systematic reviews, randomised trials, and observational studies. The review was considered to be a descriptive narrative review, without extensive pooling of data. No statistical methods were planned, and none used.

\section{Results \\ Reduction of upper gastrointestinal bleeding}

Table 1 summarises evidence relating to the outcomes of complicated upper gastrointestinal bleeding and/or symptomatic ulcer from three large randomised trials powered to detect these events (34,460 patients; [17-19]), and six meta-analyses of randomised double blind trials $(52,474$ patients in total, 44,415 of whom were not in one of the large randomised trials; [20-25]). Some of the metaanalyses include information from the large randomised 
trials, with some inevitable, but limited, duplication. The number of events was as low as 11 in one meta-analysis [21] and as high as 283 in one large randomised trial [19]. Whether the outcome was complicated bleeding events, symptomatic ulcers, or the combination, the rate with coxibs was consistently about half that with NSAIDs. In randomised trials, coxibs had significantly lower rates for upper gastrointestinal bleeding, symptomatic ulcers, endoscopic ulcers, anaemia, and withdrawal due to gastrointestinal symptoms (Table 2). For endoscopic ulcers, benefits for coxib over NSAID were of the same absolute magnitude (number needed to prevent 8 ) with or without low dose aspirin [25].

Three large observational studies [26-28] with 3,093 bleeding events compared NSAIDs and coxibs in clinical practice (Table 1). Each of these studies noted that patients receiving coxibs had more gastrointestinal risk factors than those receiving NSAIDs (channelling bias), and adjusted risk estimates for this confounding. Each of them used the outcome of hospital admission for gastrointestinal bleeding, usually upper gastrointestinal bleeding. The number of events with particular treatments could be low; only 17 admissions occurred with NSAID in one [26], and only four with coxibs in another [27]. Despite the relative paucity of events, the risk of hospital admission with coxib was about half that with NSAID. Clinical practice produced the same magnitude of reduction for coxib compared with NSAID as did clinical trials.

\section{Reduction of lower gastrointestinal bleeding}

Lower gastrointestinal bleeding has not been extensively studied. In the 1990s, using radioactive indium-labelled white cells, it was shown that faecal excretion of white cells (a marker of intestinal inflammation) was elevated with oral NSAID. Calprotectin, a calcium binding protein found in neutrophilic granulocytes, monocytes, and macrophages, which resists faecal degradation was also used as a marker. Use of the test in 312 patients taking NSAIDs showed that $44 \%$ had raised faecal calprotectin concentrations, much the same as estimates with indium studies [29]. A retrospective analysis of a large $(8,000$ patient $)$ randomised trial comparing daily rofecoxib $50 \mathrm{mg}$ with naproxen $1000 \mathrm{mg}$ used three markers for lower gastrointestinal bleeding (gross rectal bleeding with haemoglobin decrease of $20 \mathrm{~g} / \mathrm{L}$ or admission; haemoglobin decrease, positive faecal blood, no upper gastrointestinal bleeding; admission for lower perforation, obstruction, ulceration or diverticulitis) [30]. It showed a significant reduction of these events (by about 50\%) with coxib compared with NSAID, and that lower gastrointestinal bleeding was about $40 \%$ of total (upper plus lower) gastrointestinal bleeding events. A more recent randomised trial [6] compared celecoxib $400 \mathrm{mg}$ daily with placebo and naproxen $1000 \mathrm{mg}$ plus omeprazole $20 \mathrm{mg}$ daily, in 360 healthy volunteers over two weeks. Capsule endoscopy found significantly more small bowel mucosal breaks per patient with celecoxib ( 0.3 breaks per patient on average) than with placebo (0.1), but many more with naproxen plus omeprazole (3.0).

Another marker of blood loss from the bowel may be anaemia. Oral diclofenac $150 \mathrm{mg}$ daily produced anaemia in $10 \%$ of about 310 patients in 12 weeks [31]. Hooper et al [24] noted a significantly lower rate of anaemia with coxibs compared with NSAIDs (Table 2). A large metaanalysis of celecoxib trials using clinical trial reports to ascertain adverse events used two markers of anaemia, a haemoglobin fall of $\geq 20 \mathrm{~g} / \mathrm{L}$, or a haematocrit fall of $\geq 5 \%$ by the end of the study [25]. Celecoxib and placebo were not significantly different, while rates with celecoxib were always lower than those with NSAID, with numbers needed to prevent one case of 92 and 18 for haemoglobin and haematocrit respectively compared with NSAID.

\section{NSAID plus PPI}

Only three upper gastrointestinal bleeds were noted in a meta-analysis of randomised trials using NSAID plus PPI vs NSAID alone ([24]; Table 2), and only 18 symptomatic ulcers. NSAIDs plus PPI had lower rates of endoscopic ulcer and withdrawal due to gastrointestinal symptoms, though with only 48 events for the latter calculation (Table 2).

Two randomised trials $[32,33]$ have directly compared celecoxib 200 or $400 \mathrm{mg}$ daily with NSAID plus PPI (diclofenac $150 \mathrm{mg}$ plus omeprazole $20 \mathrm{mg}$ daily, or naproxen $750 \mathrm{mg}$ plus lanzoprazole $30 \mathrm{mg}$ daily). Both were conducted in patients with a previous ulcer bleed, and who needed NSAID for arthritis. After ulcer healing, patients were randomised to treatments over six months. Serious gastrointestinal complications (bleeding events) were no different for celecoxib than NSAID plus PPI ( $4.2 \%$ vs $6.0 \%$; relative risk $0.7,95 \%$ confidence interval 0.3 to 1.5 ). There were similar rates of discontinuations due to adverse events ( $4.5 \%$ vs $3.8 \%$; relative risk $1.2,0.5$ to 2.8), but dyspepsia was significantly more common with coxib than NSAID plus PPI ( $15 \%$ vs $7 \%$; relative risk $2.1,1.3$ to 3.6$)$.

Lower gastrointestinal mucosal breaks were more common with naproxen plus omeprazole than coxib or placebo [6]. Two observational studies using capsule endoscopy also found high levels of small bowel injury taking diclofenac $150 \mathrm{mg}$ plus omeprazole $40 \mathrm{mg}$ daily in volunteers [34] and in patients with NSAID use for three months or more plus some form of gastroprotection [35]. 


\section{Large randomised trials}

Bombardier et al. N Engl ] Med 2000 343: I520-1528 [i7]

Randomised trial powered for PUB outcome, comparing $50 \mathrm{mg}$ rofecox

\section{$\mathrm{n}=8,076$}

Silverstein et al. JAMA 2000284 1247-1255 [18]
Randomised trial powered for PUB outcome, comparing $800 \mathrm{mg}$ celecoxib with $2400 \mathrm{mg}$ ibuprofen

Patients with OA or RA, $\geq 18$ and $150 \mathrm{mg}$ diclofenac daily
Confirmed clinical upper $\mathrm{G}$ events (perforation, bleeding symptomatic ulcer)

Confirmed upper Gl ulcers and complication (bleeding, perforation, obstruction)
177 events, 53 complicated

Confirmed events at $2.1 / 100$ pt years

with rofecoxib, 4.5 with naproxen

Complicated 0.6 and 1.4 per 100 pt years

83 events including symptomatic ulcers, 35 complicated

Confirmed events at 2.1/100 pt years

with celecoxib, 3.5 with NSAID

Complicated at 0.8 and $\mathrm{I} .5 \mathrm{per} 100 \mathrm{pt}$ years

\section{Confirmed upper Gl ulcers and} complication (bleeding. perforation, obstruction)
283 events, I I 2 complicated
Confirmed events at $1.0 \%$ with
lumiracoxib, $1.5 \%$ with NSAID
Complicated events at $0.3 \%$ with
lumiracoxib, $0.9 \%$ with NSAID

0.5 (0.3 to 0.6$)$

$0.4(0.2$ to 0.8$)$ 665-674 [19]

\section{Meta-analyses of randomised trials}

\section{Langman et al. JAMA 1999 282: \\ 1929-1933 [20]}

Goldstein et al. Am J

Gastroenterol 2000 95: 1681-

1690 [2I]

Edwards et al. Pain 2004 II I:

286-296 [22]
Presecified meta-analysis of eight randomised trials of rofecoxib versus NSAIDs

Meta-analysis of I 4 randomised trials of celecoxib versus NSAIDs

years $n=11,008$

Meta-analysis of nine randomised OA or RA patients, $n=5,726$ trials of valdecoxib versus NSAIDs $=5,435$
OA patients, mean age 63 years $n$

Confirmed clinical upper $\mathrm{Gl}$ events (perforation, bleed, ulcer)

35 confirmed complicated events Complicated events at I.3/I00 pt years with rofecoxib, 2.6 with NSAID

Confirmed clinical upper $\mathrm{G}$ events (perforation, bleed, ulcer)

11 confirmed complicated events Complicated events at $0.2 / 100 \mathrm{pt}$ years with celecoxib, I.7 with NSAID

Clinically significant upper G bleed
10 confirmed complicated events Complicated event rate $0.1 \%$ with valdecoxib, $0.4 \%$ with NSAID
$0.5(0.3$ to I. 0$)$

$0.2(0.1$ to 0.5$)$

$0.2(0.04$ to 0.8$)$ 
Meta-analysis of eight randomised

$538[23]$

trials of valdecoxib versus NSA

OA or RA patients, mean age 58 years $n=7,434$

Confirmed clinical upper Gl events (perforation, bleed, ulcer)

8 symptomatic ulcers, Symptomatic + complicated $0.8 \%$ with Coxib, $3.3 \%$ with NSAID

Complicated $0.2 \%$ with valdecoxib, $0.5 \%$

Variety of outcomes reported, including serious gastrointestin ulcers

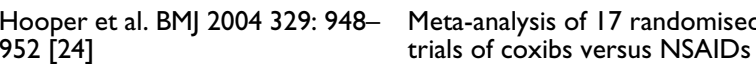

$n=25,564$ $\begin{array}{ll}\text { complica } & \text { ulcers } \\ & \end{array}$

Moore et al. Arth Res Ther 2005 7:R644-R655 [25]
Meta-analysis of 31 randomised trials of celecoxib versus NSAIDs
OA or RA $n=39,605(31,171$ in Variety of outcomes reported analysis of ulcers and bleeds)

\section{including clinical}

I 4 serious gastrointestinal

complications, $0.36 \%$ with coxib, $0.73 \%$ with NSAID 288 symptomatic ulcers, $0.8 \%$ with coxib,

184 clinical ulcers or bleeds, $0.4 \%$ with celecoxib, $0.9 \%$ with NSAID
$0.3(0.2$ to 0.4$)$

$0.4(0.1$ to 0.9$)$

\section{Large observational studies}

\section{Mamdani et al. BMJ 2002 325:} 624-630 [26]
Observational cohort study Users of NSAID, coxib, or non 144,000 users. Total population about
Hospital admission for upper gastrointestinal bleeding
82 events with controls, 17 with NSAID, 75 with coxib

Rofecoxib, but not celecoxib had significantly greater association with bleeding than controls

2,875 events on NSAID, 4 on coxib Adjusted relative risk users. Total 26,000 incident case of upper gastrointestinal haemorrhage

gastrointestinal bleeding in high risk patients

Population based case-control study non users. 780 incident cases in
Hospital admission for upper gastrointestinal bleeding
Users of NSAID, coxibs, and patients with high risk of gastrointestinal bleeding
35 patients had been exposed to coxib (4.5\%)

97 patients had been exposed to NSAID (I2\%)

Rofecoxib, but not celecoxib had significantly greater association with bleeding than controls
Celecoxib compared with NSAID $0.2(0.1$ to $0.4)$ Rofecoxib compared with NSAID $0.5(0.3$ to I.0)

$0.4(0.1$ to 1.0$)$

$0.4(0.3$ to 0.5$)$ 
Table 2: Number of events on which overall conclusions about the efficacy of gastrointestinal protection strategies were based in a systematic review [24]

\begin{tabular}{lccc}
\hline & & Number of events recorded \\
\cline { 2 - 4 } Outcome & Coxib & NSAID + PPI & NSAID + H2A \\
\hline Serious gastrointestinal complications & $\mathbf{2 2 6}$ & 3 & 1 \\
Symptomatic ulcers & $\mathbf{4 5 2}$ & 18 & $\mathbf{2 8}$ \\
Endoscopic ulcer & $\mathbf{5 2 2}$ & $\mathbf{2 8 I}$ & $\mathbf{4}$ \\
Anaemia & $\mathbf{4 6 4}$ & none & 57 \\
Withdrawal due to gastrointestinal symptoms & $\mathbf{2 1 7}$ & 48 & 57 \\
\hline
\end{tabular}

Data from Hooper et al, 2004 [24]. The numbers show the actual numbers of events reported for each outcome in the paper, and the bold numbers indicate those where event rates were significantly lower with the strategy used than with NSAID alone

\section{NSAID plus H2A}

The only evidence for efficacy for histamine antagonists with NSAID was for endoscopic ulcers (Table 2). There was no evidence of efficacy for histamine antagonists protecting against lower bowel injury.

\section{Appropriate prescribing}

We found 11 studies related to the appropriateness of use of gastroprotective strategies in patients using NSAIDs [36-46] (Table 3). These studies included 1.56 million patients, of whom 911,000 were recipients of NSAIDs.

Eight of the 11 studies reported that large proportions of patients with gastrointestinal risk factors (including age $\geq$ 65 years) were not receiving appropriate gastroprotection. In what appeared to be mainly primary care populations, non-use of gastroprotection in patients with at least one gastrointestinal risk factor was about $73 \%$ to $90 \%$ in the USA [37,44], 76\% in Italy [38], 87\% in Holland [39], 65\% in Canada [40], and 76\% in the UK [45]. A study in secondary care in the UK found no gastroprotection in $76 \%$ of patients with at least one gastrointestinal risk factor [46], but gastroprotection non-use was lower at $25 \%$ in a cohort of patients following a diagnosed ulcer or bleed [41]. Pooling these 11 studies (Figure 1), $76 \%$ of the patients with at least one gastrointestinal risk factor did not receive a prescription for a gastroprotective agent.

Four of the 11 studies made some comment on the adequacy or appropriateness of prescribing of NSAIDs and coxibs, with or without gastroprotection. It was not always clear what specific guidelines were used to judge appropriateness, and results varied greatly. Two Dutch studies $[36,42]$ agreed on the adequacy of gastroprotection, at $55 \%$ and $65 \%$ respectively. Both defined inadequate prescribing as a lower dose $\mathrm{H} 2 \mathrm{~A}$. In Canada prescribing was deemed appropriate in 33\% of patients with no risk factors, and in $74 \%$ of those with at least one risk factor [43]. By contrast, in UK secondary care only $8 \%$ of NSAID users were deemed to have appropriate treatment [46], and of those prescribed gastroprotection, 56\% were prescribed PPI, without comment on whether doses of other gastroprotective agents were effective.

Three studies $[36,43,45]$ commented on factors associated with a higher propensity to be prescribed gastroprotection. Consistently mentioned were having two or more risk factors, older age, and history of prior bleeding.

Three further studies [47-49] (Table 1) confirmed that gastroprotection was not used in about $80 \%$ of NSAID users, while not providing information about risk factors.

\section{Adherence}

We could find only a single study examining adherence to gastroprotection. Sturkenboom et al [36] followed 784 patients receiving PPI or H2A with NSAID. Half the users of H2A had become non-adherent after about 100 days, rising to about $70 \%$ by a year. Adherence was better with PPI, but non-adherence was about $40 \%$ by a year, and had risen to about $60 \%$ by the longest follow up of two years.

In a cohort of 711 subjects who stopped their NSAID and who were followed up for up to two years [36], about $40 \%$ had at least one additional prescription for acid suppressing medicine after stopping NSAID, and somehat more than $30 \%$ had at least two prescriptions.

\section{Discussion}

Current UK clinical guidance on NSAID use [50] includes the following risk factors for developing an NSAIDinduced gastrointestinal adverse event.

- Age of 65 years and over.

- Previous history of gastroduodenal ulcer, gastrointestinal bleeding, or gastroduodenal perforation.

- Concomitant use of medications that are known to increase the likelihood of upper-gastrointestinal adverse events (anticoagulants, aspirin, including low-dose aspirin, and corticosteroids). 


\section{Reference}

Study design

Population

Main outcomes

\section{Adherence and appropriateness of gastroprotection prescribing}

$\begin{array}{llll}\text { Sturkenboom et al. Aliment } & \begin{array}{l}\text { Retrospective cohort study using } \\ \text { primary care database between }\end{array} & \begin{array}{l}\text { Patients aged } \geq 18 \text { years with 12 } \\ \text { months data in database }(382,000\end{array} & \begin{array}{l}\text { Adherence to gastroprotective } \\ \text { agents }\end{array}\end{array}$ Pharm Ther 2003 18: II37-II47 primary care database between months data in database (382,000 agents

Holland [36] patients; 80,000 users of NSAIDs)
Of 65, 190 patients taking NSAIDs, 784 had PPI or H2A, in about equal numbers. Patients prescribed gastroprotection were significantly older, had more risk factors, and had more cardiovascular disease

$85 \%$ of $\mathrm{H} 2 \mathrm{~A}$ prescriptions were below recommended dose $31 \%$ of patients receiving PPI were non-adherent intially, but only about $40 \%$ took PPI long term

\section{Appropriateness of gastroprotection prescribing}

Smalley et al. Arthritis Rheum 2002 46: 2195-2200 USA [37] Retrospective cohort study using
Medicaid database during 1999-
2000

Pilotto et al. Drugs Aging 2003 20:70 I-7 I I Italy [38]

Prospective study of drug use by patients aged $\geq 65$ years. 3,200 patients of 63 randomly chosen general practitioners, in 1999

Sturkenboom et al. Rheumatology 200342 (Suppl 3):iii23-iii3l Holland [39]

Retrospective cohort study using primary care database between 1997 and 2002

Hartnell et al, Am J Geriatr () Pharmacother 20042:171-180 Canada [40]

Retrospective cross-sectional study of pharmacy database for older people, $2001-2002$
Patients aged $\geq 50$ years, with 12 Frequency of use of months data, filled one NSAID gastroprotective measures 107,000 received at least one NSAID prescription) according to NSAID use and risk factors

Patients aged $\geq 65$ years Of 3,200 patients, 800 prescribed NSAID

Use of prescribed medicines

Patients aged $\geq 18$ years with 12 months data in database $(382,000$ patients; 80,000 users of NSAIDs)

Prevalence of prophylactic gastroprotective strategies, and association with risk factors

Patients aged $\geq 65$ years with 12 months data who filled

prescription for NSAID, coxib, or high-dose aspirin (14,600 older patients using NSAID or coxib)

Patients had ICD code for GI ulceration or bleeding. Veterans were predominantly male, $50 \%$ aged 65 years or older

Patients had to have at least two prescriptions for NSAID, with total duration $>100$ days
Use of gastroprotective strategies tective strategies and prescribing NSAIDs in six months following event

Adequate gastroprotection (> recommended dose of $\mathrm{H} 2 \mathrm{~A} ; \geq \mathrm{I}$
times recommended dose of PPI) $400 \mu \mathrm{g}$ misoprostol; $\geq 2$ times
Recommended gastroprotection in $9 \%$ of patients with one risk factor, $11 \%$ of those with two risk factors. Most patients had no

gastroprotection, whilst about $25 \%$ had inadequate

gastroprotection.

No information about adherence

NSAID and high-dose aspirin prescribed for $25 \%$ of patients Use of Gl protective drugs was $24 \%$ of NSAID users with at least one risk factor by virtue of age, slightly higher than for non users of NSAIDs

No information about adherence

In patients with at least one risk factor, $87 \%$ had no gastroprotective strategy

no gastroprotection reduced over time No information about adherence

Of II,000 NSAID users, 14\% received gastroprotection Of 3,600 coxib users, $5 \%$ received gastroprotection Gastroprotection not used in $65 \%$

NSAID alone used in $67 \%$ of patients with only age as a risk factor falling to $63 \%$ with one additional, and $52 \%$ with two additional risk factors

No information about adherence

$1 \%$ prescribed coxib

$20 \%$ prescribed NSAID; of these $75 \%$ prescribed gastroprotection, $25 \%$ no gastroprotection No information about adherence

One or more gastroprotective strategies used in $43 \%$ of NSAID

Of these $65 \%$ were adequate, and $35 \%$ inadequate Use of gastroprotection was linked to having 2 or more risk factors, history of ulcers, and older age $25 \%$ of NSAID users were also taking anticoagulants, corticosteroids, or low dose aspirin No information about adherence 
Sebaldt et al. Am J Manag Care

2004 10:742-750 Canada [43]

Cross-sectional study of 5,459

patients of 119 physicians

p

Primary care physicians with hgih volume NSAID prescribing practices. OA patients had to be prescribed an NSAID

Adherence to appropriate prescribing of coxibs and NSAIDs, with or without

Abraham et al. Gastroentero 2005 |29: ||7|-||78 USA [44]

Cross-sectional study of database, inked to other files $(707,000$

Various definitions of high gastrointestinal risk, including age $\geq 65$ years patients), 2002

Cross-sectional survey of primary care practice 7,598 patients in practice in total

Thompson et al. Rheumatolo 2005 44: 1308-1310 UK [45]

Price-Forbes et al. Rheumatology 2005 44:92I-924 UK [46]

Questionnaire survey of all patients attending clinics in 18 rheumatology units over 2 weeks

\section{2,846 patients, of whom 791}

coxibs. $65 \%$ of users and 373

of OA or RA

Prospective study of drug use by Patients aged $\geq 65$ years

Pilotto et al. Aliment Pharmaco Ther 2005 22: 147-I 55 Italy [[47]

patients aged $\geq 65$ years. 5,500

patients of 133 gener

Gl symptoms

Adherence to gastroprotection guidelines

267 patients receiving repeat

Prescribing according to NICE guidance

Prescribing according to $\mathrm{Gl}$ risk factors
In patients with no Gl risk factors (39\% of total), $33 \%$ of

prescribing was appropriate

In patients with at least one Gl risk factor (61\% of total), $74 \%$ of

More use of coxibs with prior bleed, more severe pain, or with concomitant warfarin

$43 \%$ of NSAID users were at high risk of GI complications $73 \%$ of these not prescribed gastroprotection $27 \%$ of these prescribed gastroprotection (I8\% NSAID plus PPI, $9 \%$ coxib)

Greater gastroprotection use with two or more risk factors

Predictors of gastroprotection were previous upper

gastrointestinal event, anticoagulant use, aspirin use,

rheumatological disease

$69 \%$ NSAID users had one or more GI risk factors; antacids prescribed in $24 \%$ of those with a risk factor $74 \%$ coxib users had one or more GI risk factors; antacids prescribed in $6 \%$ of those with a risk factor

Of NSAID users, $92 \%$ had at least one GI risk factor (mostly prolonged use, and age $\geq 65$ years); only $8 \%$ received appropriate treatment. Gastroprotective drug prescribed for 191 patients (24\%), of which $56 \%$ were PPI

Of coxib users, $97 \%$ of prescribing was appropriate, with 77 (21\%) taking gastroprotective drug

\section{NSAID use in $6 \%$}

Coxib use in $3 \%$

New prescriptions for drugs for acid-related disorders in $13 \%$ of NSAID users, $6 \%$ of coxib users

No information on adherence

\section{General information about gastroprotection prescribing}

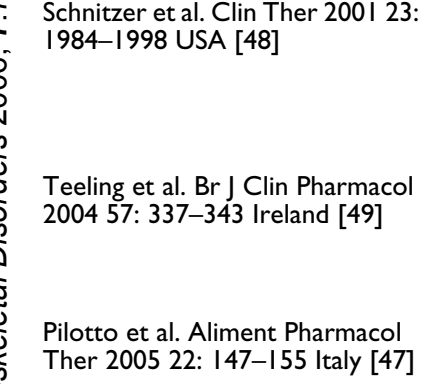

Retrospective analysis of prescription database for 1998. million new users of NSAIDs

Retrospective analysis of prescription database, 2000-2001 1.2 million people). About

\section{At least one NSAID prescription} during 1998, and no use in prior 20 days ( $<30$ days acute; $>30$ users 60 years or older

Patients aged 16 years or older prescribed an NSAID

Patients aged $\geq 65$ years

Use of prescribed NSAIDS, and

Use of gastroprotective medicines, by NSAID Gl symptoms

Use of gastroprotective medicines, by NSAID

(n) 


\section{Number of patients using NSAID}

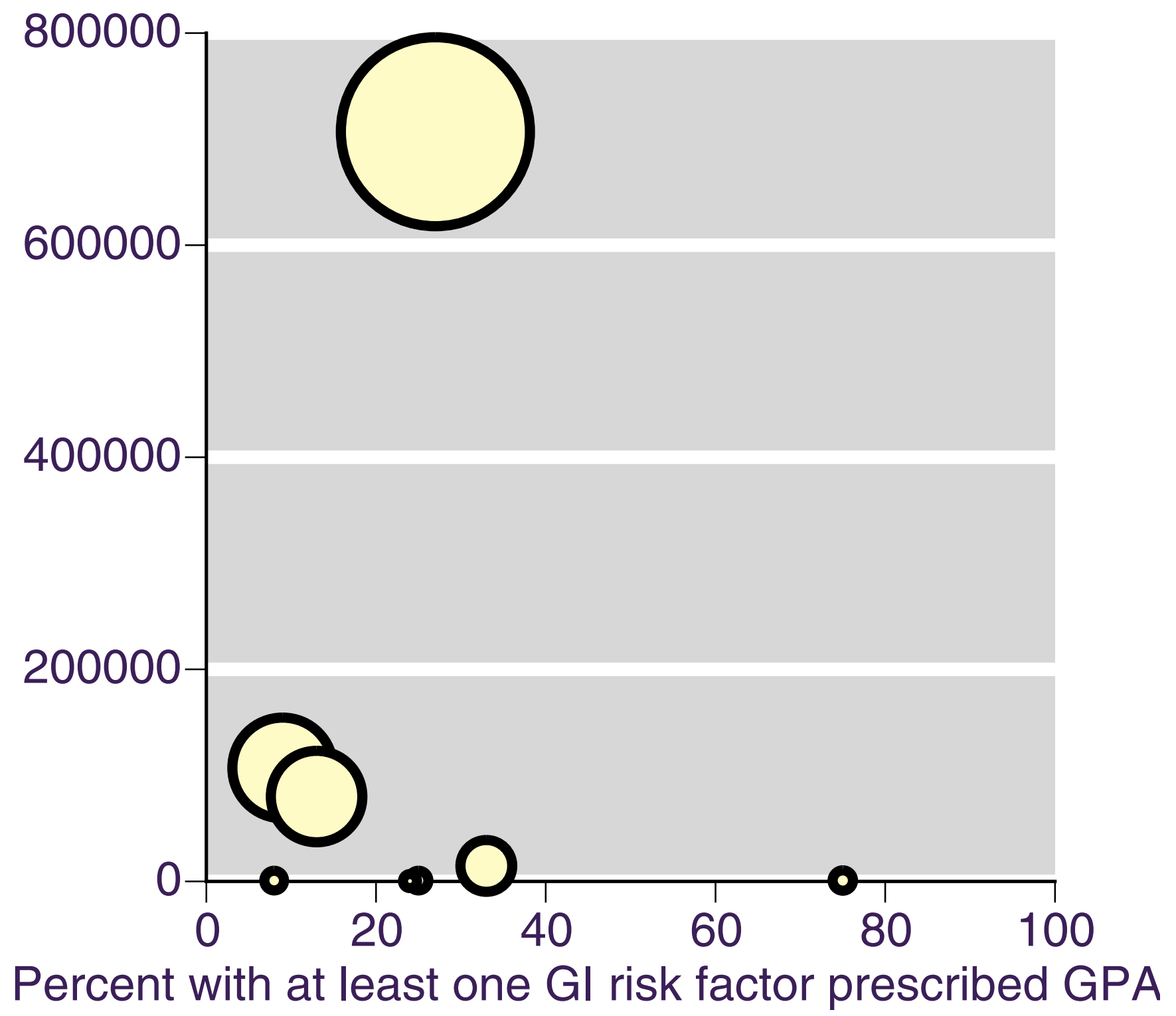

Figure I

Scatter plot showing the percentage of patients with at least one gastrointestinal risk factor prescribed an NSAID plus gastroprotective agent ( $\mathrm{H} 2 \mathrm{~A}$ or $\mathrm{PPI})$ or a coxib. The size of the symbol is proportional to the size of the study.

- Presence of serious comorbidity, such as cardiovascular disease, renal or hepatic impairment, diabetes, or hypertension.

- Requirement for a prolonged duration of NSAID use.

- Use of the maximum recommended doses of NSAIDs.

- The presence of Helicobacter pylori infection.
- Excessive alcohol use.

- Heavy smoking.

Using these criteria, many NSAID users have a risk factor, even if it is only age. A large US study found that $42 \%$ of 707,000 NSAID users were at higher risk [44], and in a recent Italian study at least one risk factor was found in $68 \%$ of NSAID users [51]. Many different guidelines exist, 
Table 4: Summary of effectiveness

\begin{tabular}{llcl}
\hline \multicolumn{1}{c}{ Strategy } & \multicolumn{1}{c}{ Efficacy } & Appropriate prescribing & Adherence \\
\hline $\begin{array}{l}\text { Upper gastrointestinal injury } \\
\text { Coxib }\end{array}$ & Extensive, robust evidence & Low & Effective \\
NSAID + PPI & Surrogate only & Low & Low adherence \\
NSAID + H2A & Surrogate only & Low & Low adherence \\
Lower gastrointestinal injury & & Low & Effective \\
Coxib & Some evidence of efficacy & Low & Low adherence \\
NSAID + PPI & Some evidence of lack of efficacy & Low & Low adherence \\
NSAID + H2A & No evidence & \\
\hline
\end{tabular}

Summarised from Hooper et al, 2004 [24].

and they consistently recommend use of gastroprotective agent (PPI or H2A) with NSAID, or use of coxib. All strategies include interventions that should precede oral NSAID use, such as lifestyle change, topical NSAIDs, paracetamol, and glucosamine; this study did not include any of these, as they are not conventionally implicated in gastrointestinal damage.

This review set out to examine the strength of evidence on particular gastroprotective strategies, whether guidance about strategies was implemented by prescribers, and whether patients were adherent to prescribed medicines. The evidence available is mixed: some points are addressed by large and coherent amounts of evidence, while for others evidence is either lacking or limited. An important limitation is that much of the information, especially in observational studies in clinical practice, does not differentiate between different NSAIDs or gastroprotective agents. Moreover, while some evidence is of the highest level from meta-analyses of high-quality randomised trials [52], other evidence is from observational studies, where testing of quality is more difficult. We do know, however, that when criteria of quality, validity, and size are met, observational studies produce similar results to randomised trials [53].

The evidence on efficacy in reducing upper gastrointestinal bleeding is considerable for coxibs. Three adequatelypowered randomised trials, and several meta-analyses of large numbers of patients in randomised trials come to the consistent conclusion that the rate of complicated upper gastrointestinal events with coxibs is about half that with NSAIDs. Rates of symptomatic ulcers, endoscopic ulcers, and withdrawal because of gastrointestinal adverse events were all about half with coxibs compared with NSAIDs. For coxibs there is also evidence, from capsule endoscopy studies, of reduced lower bowel damage compared with NSAID plus PPI. Additionally, rates of anaemia were lower with coxibs than with NSAIDs in two large meta-analyses $[24,25]$, using several definitions of anaemia. This represents a large body of evidence, with many events (Table 2), using clinical as well as surrogate out- comes, and supported by large observational studies of high quality.

Strategies of co-prescription of NSAID with either PPI or H2A do not have this degree of evidence to support reduction of serious gastrointestinal complications. One reason for is that this indication came considerably later than original licensing of these gastroprotective agents and the surrogate marker of endoscopic ulcers was used. Absence of large outcome trials does not mean that they do not work, and we have no direct comparisons of different strategies in large numbers of patients with clinical events as outcomes. Even combined, randomised trials of these strategies had only four clinical events, and only the surrogate marker of endoscopic ulcer supports efficacy. Because we have two direct comparisons of coxib with NSAID plus PPI in two randomised trials in high-risk patients immediately after healing of a previous ulcer, and with no statistically significant difference, we can probably assume at least some degree of upper gastrointestinal protection with PPI use, although conclusions from these trials may not apply to those without a previous ulcer. For $\mathrm{H} 2 \mathrm{~A}$, no such assumption is justified. We have evidence from one large randomised trial and two cohort studies that coxibs cause fewer problems in the lower bowel than NSAID and PPI. Use of NSAID plus PPI, and especially $\mathrm{H} 2 \mathrm{~A}$, therefore fall some way short in terms of gastrointestinal protection.

The evidence from observational studies is that most patients at higher risk of gastrointestinal problems with NSAIDs, by virtue of age or previous history, are not usually given gastroprotection. Most of the studies relate to the period 2000-2002, and it may be that the introduction of better guidance since then has led to a change, but we could not find evidence of that. Two further studies published in 2006 confirm low use of gastroprotection in patients with gastrointestinal risk factors taking NSAIDs. One in primary care [54] reported a large uptake of coxibs over 1998-2002, and low use of gastroprotection with NSAIDs at any time over that period in patients aged 65 years or older. The second [55] surveyed prescribing by 
rheumatology specialists in 2003/4, and found that even in patients with four risk factors for gastrointestinal ulceration, gastroprotection was co-prescribed with NSAIDs in no more than $40 \%$ of patients.

The evidence we have about prescribing is that guidance has not generally been followed: three quarters of patients with at least one gastrointestinal risk factor did not receive a prescription for a gastroprotective agent. In individual studies in primary care adherence prescribing guidelines varied from $9 \%$ to $27 \%$ (Figure 1). It should be emphasised that this observational evidence is substantial, based on almost 1.6 million patients, over 900,000 of whom were prescribed NSAIDs, and studies often specifically tested adherence to evidence-based guidelines (as in over 700,000 patients [44]).

Patient adherence to prescribed gastroprotection was described in only one study [36], which found that adherence to NSAID plus PPI or H2A declined rapidly, so that after about six months the majority of patients were not taking the gastroprotection prescribed. This is in accord with many other studies of adherence to medicines. Adherence to low dose aspirin was only $47 \%$ after a year [56], was as low as 33\% for statin and antihypertensive medicines when prescribed together [57], and was even about 20\% with immunosuppressants following renal transplantation [58]. Coxibs cause less gastrointestinal harm, thus limiting or eliminating the need for co-prescription and the problem of adherence.

We chose not to extend this review beyond the narrow bound of gastroprotection, but other issues are important. For instance, NSAID and coxib clinical trials have a range of common adverse events [25]. Other serious adverse events, like cardiovascular problems, have to be considered, and it seems increasingly likely that these will be related to individual NSAIDs or coxibs rather than coxibs versus NSAIDs $[12,13]$. Long-term acid suppression itself may be associated with adverse events, including hip fracture [59] and vertebral fracture [60]. Patient choice is an increasingly important issue, and interestingly no experienced patient with knee osteoarthritis chose conventional NSAID therapy when presented with information about common therapies [61].

In this review the use of observational studies to evaluate adherence to clinical guidelines is not a limitation: the observational studies report what is happening in clinical practice. Moreover, many of these observational studies were large and inclusive, minimising potential for bias. Evidence from clinical trials (randomised, and controlled) and clinical practice (observational studies) tend to be similar when criteria of quality, validity and size are met [60]. It is seen for cardiovascular effects of coxibs and
NSAIDs in meta-analyses of clinical trials [12] and observational studies [13].

For a strategy to be effective, it has to translate efficacy from clinical trials to clinical practice. With NSAIDs, but not coxibs, gastrointestinal protection can be delivered only if those patients who need gastroprotection are given it, and those who are given gastroprotection take it. Effectiveness evidence is summarised for the different strategies is in Table 4. The evidence for efficacy of co-prescription of gastroprotective agents in protecting the upper gastrointestinal tract is largely limited to the surrogate measure of endoscopic ulcers, though it is probable that bleeding events would be reduced. Such evidence we have suggests that PPIs have no efficacy in protecting the small bowel. From clinical practice, the evidence is that those patients who need gastroprotection do not get it, while those who get it do not take it. As a strategy, this is a considerable way short of ideal.

\section{Conclusion}

There is considerable evidence that patients who need gastroprotection because they have at least one gastrointestinal risk factor do not get it, despite clear guidelines suggesting that they should. There is limited evidence that those who get gastroprotection in the form of PPI or H2A do not take it. As a strategy, this is a considerable way short of ideal.

\section{Abbreviations}

PPI: proton pump inhibitor

H2A: histamine-2 receptor antagonist

NSAID: non-steroidal anti-inflammatory drug

Coxib: cyclooxygenase-2 selective inhibitor

\section{Competing interests}

RAM, HJM and CP have received consulting and/or lecture fees from pharmaceutical companies and other organisations. The authors have received research support from charities and government sources at various times. No author has any direct stock holding in any pharmaceutical company.

\section{Authors' contributions}

RAM was involved with the original concept, planning the study, data extraction, analysis, and preparing a manuscript; SD with data extraction, analysis, and writing; CP and HJM with writing and advice. All authors read and approved the final manuscript.

\section{Acknowledgements}

Pain Research is supported in part by the Oxford Pain Research Trust, and this work was also supported by an unrestricted educational grant from 
Pfizer Ltd. Neither organisation had any role in design, planning, execution of the study, or in writing the manuscript. The terms of the financial support from Pfizer included freedom for authors to reach their own conclusions, and an absolute right to publish the results of their research, irrespective of any conclusions reached. Pfizer did have the right to view the final manuscript before publication, and did so.

\section{References}

I. Breivik H, Collett B, Ventafridda V, Cohen R, Gallacher D: Survey of chronic pain in Europe: Prevalence, impact on daily life, and treatment. Eur J Pain 2006, 10:287-333.

2. Sprangers MA, de Regt EB, Andries F, van Agt HM, Bijl RV, de Boer JB, Foets M, Hoeymans N, Jacobs AE, Kempen GI, et al:: Which chronic conditions are associated with better or poorer quality of life? J Clin Epidemiol 2000, 53:895-907.

3. Hernández-Diaz S, García Rodriguez LA: Association between nonsteroidal anti-inflammatory drugs and upper gastrointestinal tract bleeding and perforation: An overview of epidemiological studies published in the 1990s. Arch Intern Med 2000, 160:2093-2099.

4. Allison MC, Howatson AG, Torrance Cl, Lee FD, Russell RI: Gastrointestinal damage associated with the use of nonsteroidal antiinflammatory drugs. N Engl J Med 1992, 327:749-754.

5. Lanas A, Serrano P, Bajador E, Esteva F, Benito R, Sainz R: Evidence of aspirin use in both upper and lower gastrointestinal perforation. Gastroenterology 1997, I I 2:683-689.

6. Goldstein JL, Eisen GM, Lewis B, Gralnek IM, Zlotnick S, Fort JG Video capsule endoscopy to prospectively assess small bowel injury with celecoxib, naproxen plus omeprazole, and placebo. Clin Gastroenterol Hepatol 2005, 3: |33-141.

7. Henry D, Page J, Whyte I, Nanra R, Hall C: Consumption of nonsteroidal anti-inflammatory drugs and the development of functional renal impairment in elderly subjects. Results of a case-control study. Br J Clin Pharmacol 1997, 44:85-90.

8. Griffin MR, Yared A, Ray WA: Nonsteroidal antiinflamatory drugs and acute renal failure in elderly persons. Am J Epidemiol 2000, I 5 1:488-496.

9. Page J, Henry D: Consumption of NSAIDs and the development of congestive heart failure in elderly patients: An underrecognized public health problem. Arch Intern Med 2000 1 60:777-784.

10. Garcia Rodriguez LA, Hernandez-Diaz S: Non-steroidal antiinflammatory drugs as a trigger of clinical heart failure. Epidemiology 2003, I 4:240-246.

II. White WB, Faich G, Borer JS, Makuch RW: Cardiovascular thrombotic events in arthritis trials of the cyclooxygenase-2 inhibitor celecoxib. Am J Cardiol 2003, 92:4 II-4I8.

12. Kearney PM, Baigent C, Godwin J, Halls H, Emberson JR, Patrono C: Do selective cyclo-oxygenase- 2 inhibitors and traditional non-steroidal anti-inflammatory drugs increase the risk of atherothrombosis? Meta-analysis of randomised trials. BMJ 2006, 332:1302-1308.

13. Hernandez-Diaz S, Varas-Lorenzo C, Garcia Rodriguez LA: Nonsteroidal antiinflammatory drugs and the risk of acute myocardial infarction. Basic Clin Pharmacol Toxicol 2006, 98:266-274.

14. Moore RA, Phillips C]: Cost of NSAID adverse effects to the NHS. J Med Econ 1999, 2:45-55.

15. Lemeshow AR, Blum RE, Berlin JA, Stoto MA, Colditz GA: Searching one or two databases was insufficient for meta-analysis of observational studies. I Clin Epidemiol 2005, 58:867-873.

16. Ruppen W, Derry S, McQuay HJ, Moore RA: Incidence of epidural hematoma, infection and neurological injury in obstetric patients with epidural analgesia/anesthesia: meta-analysis. Anesthesiology 2006, 105:394-399.

17. Bombardier C, Laine L, Reicin A, Shapiro D, Burgos-Vargas R, Davis B, Day R, Ferraz MB, Hawkey CJ, Hochberg MC, VIGOR Study Group: Comparison of upper gastrointestinal toxicity of rofecoxib and naproxen in patients with rheumatoid arthritis. N Engl J Med 2000, 343: I520-1528.

18. Silverstein FE, Faich G, Goldstein JL, Simon LS, Pincus T, Whelton A Makuch R, Eisen G, Agrawal NM, Stenson WF, et al.: Gastrointestinal toxicity with celecoxib vs nonsteroidal anti-inflammatory drugs for osteoarthritis and rheumatoid arthritis: the
CLASS study: A randomized controlled trial. JAMA 2000, 284: $1247-1255$

19. Schnitzer TJ, Burmester GR, Mysler E, Hochberg MC, Doherty M, Ehrsam E, Gitton X, Krammer G, Mellein B, Matchaba P, TARGET Study Group: Comparison of lumiracoxib with naproxen and ibuprofen in the Therapeutic Arthritis Research and Gastrointestinal Event Trial (TARGET), reduction in ulcer complications: randomised controlled trial. Lancet 2004, 364:665-674.

20. Langman MJ, Jensen DM, Watson DJ, Harper SE, Zhao PL, Quan H, Bolognese JA, Simon TJ: Adverse upper gastrointestinal effects of rofecoxib compared with NSAIDs. JAMA 1999, 282:1929-1933.

21. Goldstein JL, Silverstein FE, Agrawal NM, Hubbard RC, Kaiser J, Maurath C], Verburg KM, Geis GS: Reduced risk of upper gastrointestinal ulcer complications with celecoxib, a novel COX-2 inhibitor. Am / Gastroenterol 2000, 95: I68I-1690.

22. Edwards JE, McQuay HJ, Moore RA: Efficacy and safety of valdecoxib for treatment of osteoarthritis and rheumatoid arthritis: systematic review of randomised controlled trials. Pain 2004, I I I:286-296.

23. Goldstein JL, Eisen GM, Agrawal N, Stenson WF, Kent JD, Verburg KM: Reduced incidence of upper gastrointestinal ulcer complications with the $\mathbf{C O X}-2$ selective inhibitor, valdecoxib. Aliment Pharmacol Ther 2004, 20:527-538.

24. Hooper L, Brown TJ, Elliott R, Payne K, Roberts C, Symmons D: The effectiveness of five strategies for the prevention of gastrointestinal toxicity induced by non-steroidal anti-inflammatory drugs: systematic review. BM/ 2004, 329:948.

25. Moore RA, Derry S, Makinson GT, McQuay HJ: Tolerability and adverse events in clinical trials of celecoxib in osteoarthritis and rheumatoid arthritis: systematic review and meta-analysis of information from clinical trial reports. Arthritis Res Ther 2005, 7:R644-R665.

26. Mamdani M, Rochon PA, Juurlink DN, Kopp A, Anderson GM, Naglie G, Austin PC, Laupacis A: Observational study of upper gastrointestinal haemorrhage in elderly patients given selective cyclo-oxygenase-2 inhibitors or conventional non-steroidal anti-inflammatory drugs. BMJ 2002, 325:624.

27. MacDonald TM, Morant SV, Goldstein JL, Burke TA, Pettitt D: Channelling bias and the incidence of gastrointestinal haemorrhage in users of meloxicam, coxibs, and older, non-specific non-steroidal anti-inflammatory drugs. Gut 2003 52: 1265-1270.

28. Norgard B, Pedersen L, Johnsen SP, Tarone RE, McLaughlin JK, Friis $\mathrm{S}$, Sorensen HT: COX-2-selective inhibitors and the risk of upper gastrointestinal bleeding in high-risk patients with previous gastrointestinal diseases: a population-based casecontrol study. Aliment Pharmacol Ther 2004, 1 9:8। 7-825.

29. Tibble JA, Sigthorsson G, Foster R, Scott D, Fagerhol MK, Roseth A, Bjarnason I: High prevalence of NSAID enteropathy as shown by a simple faecal test. Gut 1999, 45:362-366.

30. Laine L, Connors LG, Reicin A, Hawkey C], Burgos-Vargas R, Schnitzer TJ, Yu Q, Bombardier C: Serious lower gastrointestinal clinical events with nonselective NSAID or coxib use. Gastroenterology 2003, I 24:288-292.

31. Tugwell PS, Wells GA, Shainhouse JZ: Equivalence study of a topical diclofenac solution (pennsaid) compared with oral diclofenac in symptomatic treatment of osteoarthritis of the knee: a randomized controlled trial. J Rheumatol 2004, 3 I :2002-20l2.

32. Chan FK, Hung LC, Suen BY, Wu JC, Lee KC, Leung VK, Hui AJ, To KF, Leung WK, Wong VW, et al.: Celecoxib versus diclofenac and omeprazole in reducing the risk of recurrent ulcer bleeding in patients with arthritis. N Engl J Med 2002, 347:2104-2110.

33. Lai KC, Chu KM, Hui WM, Wong BC, Hu WH, Wong WM, Chan AO, Wong J, Lam SK: Celecoxib compared with lansoprazole and naproxen to prevent gastrointestinal ulcer complications. Am J Med 2005, I | 8: | 27| |- 278.

34. Maiden L, Thjodleifsson B, Theodors A, Gonzalez J, Bjarnason I: A quantitative analysis of NSAID-induced small bowel pathology by capsule enteroscopy. Gastroenterology 2005, I 28: I |72-। |78. 
35. Graham DY, Opekun AR, Willingham FF, Qureshi WA: Visible small-intestinal mucosal injury in chronic NSAID users. Clin Gastroenterol Hepatol 2005, 3:55-59.

36. Sturkenboom MC, Burke TA, Tangelder MJ, Dieleman JP, Walton S, Goldstein JL: Adherence to proton pump inhibitors or H2receptor antagonists during the use of non-steroidal antiinflammatory drugs. Aliment Pharmacol Ther 2003, I 8: I I37-I I 47.

37. Smalley W, Stein CM, Arbogast PG, Eisen G, Ray WA, Griffin M: Underutilization of gastroprotective measures in patients receiving nonsteroidal antiinflammatory drugs. Arthritis Rheum 2002, 46:2195-2200

38. Pilotto A, Franceschi M, Leandro G, Di Mario F, Geriatric Gastroenterology Study Group: NSAID and aspirin use by the elderly in general practice: effect on gastrointestinal symptoms and therapies. Drugs Aging 2003, 20:70I-7I0.

39. Sturkenboom MC, Burke TA, Dieleman JP, Tangelder MJ, Lee F, Goldstein JL: Underutilization of preventive strategies in patients receiving NSAIDs. Rheumatology (Oxford) 2003, 42(Suppl 3):iii23-3i.

40. Hartnell NR, Flanagan PS, MacKinnon NJ, Bakowsky VS: Use of gastrointestinal preventive therapy among elderly persons receiving antiarthritic agents in Nova Scotia, Canada. Am J Geriatr Pharmacother 2004, 2:17|-I80.

41. Dominick KL, Bosworth HB, Jeffreys AS, Grambow SC, Oddone EZ, Horner RD: Nonsteroidal antiinflammatory drug use among patients with GI bleeding. Ann Pharmacother 2004, 38: | | 59- | I64.

42. Herings RM, Goettsch WG: Inadequate prevention of NSAIDinduced gastrointestinal events. Ann Pharmacother 2004, 38:760-763.

43. Sebaldt RJ, Petrie A, Goldsmith CH, Marentette MA: Appropriateness of NSAID and Coxib prescribing for patients with osteoarthritis by primary care physicians in Ontario: results from the CANOAR study. Am J Manag Care 2004, 10:742-750.

44. Abraham NS, El-Serag HB, Johnson ML, Hartman C, Richardson P, Ray WA, Smalley W: National adherence to evidence-based guidelines for the prescription of nonsteroidal anti-inflammatory drugs. Gastroenterology 2005, I29: | I7|-| |78.

45. Thompson PW, Tee L, McBride J, Quincey D, Strat Liddiard G: Longterm NSAID use in primary care: changes over a decade and NICE risk factors for gastrointestinal adverse events. Rheumatology (Oxford) 2005, 44:1308-1310.

46. Price-Forbes AN, Callaghan R, Allen ME, Rowe IF: A regional audit of the use of COX-2 selective non-steroidal anti-inflammatory drugs (NSAIDs) in rheumatology clinics in the West Midlands, in relation to NICE guidelines. Rheumatology (Oxford) 2005, 44:92I-924.

47. Pilotto A, Franceschi M, Vitale DF, Zaninelli A, Masotti G, Rengo F, F.I.R.I. and Sofia Project Investigators: Upper gastrointestinal symptoms and therapies in elderly out-patients, users of non-selective NSAIDs or coxibs. Aliment Pharmacol Ther 2005, 22:147-155.

48. Schnitzer TJ, Kong SX, Mavros PP, Straus WL, Watson DJ: Use of nonsteroidal anti-inflammatory drugs and gastroprotective agents before the advent of cyclooxygenase-2-selective inhibitors: analysis of a large United States claims database. Clin Ther 200I, 23: 1984-1998.

49. Teeling M, Bennett K, Feely J: Have COX-2 inhibitors influenced the co-prescription of anti-ulcer drugs with NSAIDs? Br J Clin Pharmacol 2004, 57:337-343.

50. Prodigy [http://www.prodigy.nhs.uk/guidance.asp?gt=Nonsteroi dal\%20anti-inflammatory\%20drugs\%20(NSAIDs]. accessed 23 February 2006

51. Silvani MC, Motola D, Poluzzi E, Bottoni A, De Ponti F, Vaccheri A, Montanaro N: Gastrointestinal problems and concomitant medication in NSAID users: additional findings from a questionnaire-based study in Italy. Eur J Clin Pharmacol 2006, 62:235-24I.

52. Steinman MA, McQuaid KR, Covinsky KE: Age and rising rates of cyclooxygenase-2 inhibitor use. Results from a national survey. I Gen Intern Med 2006, 21 :245-250.

53. Garcia EB, Michaud K, Wolfe F: Gastrointestinal prophylactic therapy among patients with arthritis treated by rheumatology specialists. J Rheumatol 2006, 33:779-784.

54. Morant SV, McMahon AD, Cleland JG, Davey PG, MacDonald TM: Cardiovascular prophylaxis with aspirin: costs of supply and management of upper gastrointestinal and renal toxicity. $\mathrm{Br}$ J Clin Pharmacol 2004, 57: 188-198.

55. Chapman RH, Benner JS, Petrilla AA, Tierce JC, Collins SR, Battleman DS, Schwartz JS: Predictors of adherence with antihypertensive and lipid-lowering therapy. Arch Intern Med 2005, 165: II47-II52.

56. Butler JA, Peveler RC, Roderick P, Smith PW, Horne R, Mason JC Modifiable risk factors for non-adherence to immunosuppressants in renal transplant recipients: a cross-sectional study. Nephrol Dial Transplant 2004, 19:3|44-3|49.

57. Yang YX, Lewis JD, Epstein S, Metz DC: Chronic acid suppressive therapy and the risk of hip fracture. Gastroenterology 2005, I 28:A-138.

58. Yamaguchi T, Sugimoto T, Yamauchi M, Matsumori $Y$, Tsutsumi M, Chihara K: Multiple vertebral fractures are associated with refractory reflux esophagitis in postmenopausal women. J Bone Miner Metab 2005, 23:36-40.

59. Fraenkel L, Bogardus ST Jr, Concato J, Wittink DR: Treatment options in knee osteoarthritis: the patient's perspective. Arch Intern Med 2004, I 64: 1299-1 304

60. Moore A, McQuay H: Bandolier's Little Book of Making Sense of the Medical Evidence Oxford: Oxford University Press; 2006:206-2I5.

\section{Pre-publication history}

The pre-publication history for this paper can be accessed here:

http://www.biomedcentral.com/1471-2474/7/79/prepub

Publish with BioMed Central and every scientist can read your work free of charge

"BioMed Central will be the most significant development for disseminating the results of biomedical research in our lifetime. "

Sir Paul Nurse, Cancer Research UK

Your research papers will be:

- available free of charge to the entire biomedical community

- peer reviewed and published immediately upon acceptance

- cited in PubMed and archived on PubMed Central

- yours - you keep the copyright 